\section{Revealing the Mystery of Heredity in Grafted Fruit Trees}

\author{
Yongsheng Liu ${ }^{1}$ \\ Department of Horticulture, Henan Institute of Science and Technology, \\ Xinxiang, China, 453003
}

It is well known that most fruit trees are grafted to retain desirable qualities that do not come true from seed. Less well known is that genes may move between the rootstock and the scion by grafting, which is critical for revealing the mystery of heredity locked in the grafted fruit trees.

More than 1400 years ago, Sixie Jia mentioned pear variability in the section of $Q i$ min yao shu entitled "Pear grafting": "there are 10 seeds in every single pear fruit, only 2 seeds grow into pear tree, but others grow into birch-leaf pear tree" (Liu, 2001). Darwin (1868) noticed "certain fruit trees truly propagate their kind while growing on their own roots; but when grafted on other stocks, and by this process their natural state is manifestly affected, they produce seedlings which vary greatly, departing from the parental type in many characters." In the course of his life, Michurin (1955) not only produced more than 300 strains of horticultural plants, but also made great use of grafting as a means of influencing and improving immature plants, showing that plants can be altered by grafting if in a sufficiently early phase of development. He believed that the chief cause of bad heredity in grafted fruit trees is the rootstock onto which the old cultivar was grafted. The scion itself- the old cultivar - is little changed by the action of the rootstock; but its young organs, i.e., the seeds formed in the fruit, deviate strongly in the direction of the rootstock. Michurin's postulate is fully confirmed by the fact that wildings are never derived from the seeds of ungrafted trees if their blossoms are completely isolated from pollination by outside cultivars. All fruit trees that are not grafted but have their own roots when crossed give a greater number of cultivars with good qualities as compared

Received for publication 11 Sept. 2004.Accepted for publication 27 Dec. 2004. I thank Edward J. Steele for his helpful suggestions and valuable comments. 1E-mailysliu63@yahoo.ca. to those that are grafted onto rootstocks. This clearly shows that the plant's root system plays a very active part in the formation of the seed. Based on these findings, Michurin (1955) repeatedly warned the breeders that the crossed parental plants should be those that are not grafted but are standing on their own roots, in this way the breeding efficiency will raise 4-fold. Unfortunately, this theoretically and practically important principle and method has been totally ignored because there has been a refusal to accept the existence of graft hybrid, which has been regarded only as a type of chimera.

Over the past decades, several independent groups of scientists proved the existence of graft hybrids (Liu, 2004). It has been suggested that transformation is a probable mechanism for graft hybridization (Ohta, 1991). The whole concept of gene transfer by means of grafting is highly suggestive of a new dimension of gene movement in plants. What, then, is the basis of this gene transfer? Recently, it has been found that mRNAmay move between cells and around the plant (Lucas et al., 2001). It is well known that retrotransposons are ubiquitous in plants and play a major role in plant gene and genome evolution. Retrotransposons are mobile genetic elements that transpose through reverse transcription of an RNA intermediate (Kumar and Bennetzen, 1999). With the establishment that novel mRNA species may move between cells and around the plant, and the ability of retroviruses or retrotransposons to reverse transcribe mRNA into cDNAcapable of being integrated into the genome, mechanisms exist for the horizontal gene transfer from rootstock to scion. The questions may arise why the branches, leaves, flowers, and fruits of the grafted fruit trees hardly change at all under the influence of the rootstock; whereas the seeds are susceptible to change under the same influence of the rootstock?

Darwin (1868) used to say on the basis of his observations that there was hardly a more amazing thing in nature than the sensitivity of sex cells to external influences. Michurin (1955) emphasized repeatedly that young plant seedlings, the germ cells and seeds are highly susceptible to the influence of environmental conditions. In the field of transgenic research, transformation and regeneration of woody fruit plants are usually limited to juvenile tissues derived from seeds or seedling organs such as zygotic embryo, hypocotyls or cotyledons, whereas tissue from mature plants cannot be readily transformed (Cerera et al., 1998). Based on the above fact, I postulate that the germ cells and the embryonic cells of the plants, as well as the somatic cells of the juvenile plants, are competent cells, which can be transformed easily by foreign genes; whereas the somatic cells of the adult and old plants are non-competent cells, which are difficult to be transformed by foreign genes. I propose that the rootstock mRNA molecules being transferred into the scion and reverse transcribed into cDNA capable of being integrated into the genome of the scion's germ cells and embryonic cells, may be the main reason why the overwhelming majority of the hybrid seedlings that grow from the seeds gathered from the grafted fruit trees have undesirable properties. The time has come when further progress in our understanding of heredity in grafted fruit trees requires that we reconsider Michurin's principles and methods in fruit breeding.

\section{Literature cited}

Cerera, M., J. Juarez, A. Navarro, A.J. Pina, N. Nuran-Vila, L. Navarro, and L. Pena.1998. Genetic transformation and regeneration of mature tissues of woody fruit plants bypassing the juvenile stage. Transgenic Res. 7:51-59.

Darwin, C. 1868. The Variation of Animals and Plants under Domestication. John Murry, London.

Kumar,A. and J.L. Bennetzen. 1999. Plant retrotransposons. Annu. Rev. Genet. 33:479-532.

Liu, Y-S. 2001. The theoretical and practical significance of plant grafting in ancient and modern China. Studies History Nat. Sci. 21(4):352-361.

Liu, Y-S. 2004. Further evidence for Darwin's pangenesis. Rivista di Biologia/Biol. Forum 97:53-66.

Lucas, W.J., B-C. Yoo, and F. Kragler. 2001. RNA as a long-distance information macromolecule in plants. Nature Rev. Mol. Biol. 2:849-857.

Michurin, I.V. 1955. Collected works. Financial Economy Press, Beijing.

Ohta, Y. 1991. Graft-transformation, the mechanism for graft-induced genetic changes in higher plants. Euphytica 55:91-99. 